\title{
New and additional to what? Options for baselines to assess "new and additional" climate finance
}

\author{
Stadelmann, Martin ; Roberts, J T ; Michaelowa, Axel
}

\begin{abstract}
All major climate policy agreements - the UN Framework Convention, the Kyoto Protocol, and recently the Cancun Agreements- have stated that climate finance for developing countries will be "new and additional". However, the term "new and additional" has never been properly defined. Agreeing a system to measure a baseline from which "new and additional" funding will be calculated will be central to building trust and realising any post-Kyoto agreement. We explore eight different options for a baseline, and assess each according to several criteria: novelty to existing pledges, additionality to development assistance, environmental effectiveness, distributional consequences, and institutional and political feasibility. Only two baseline options do well on these criteria and are therefore viable: "new sources only" and "above pre-defined business as usual level of development assistance".
\end{abstract}

DOI: https://doi.org/10.1080/17565529.2011.599550

Posted at the Zurich Open Repository and Archive, University of Zurich

ZORA URL: https://doi.org/10.5167/uzh-52819

Journal Article

Accepted Version

Originally published at:

Stadelmann, Martin; Roberts, J T; Michaelowa, Axel (2011). New and additional to what? Options for baselines to assess "new and additional" climate finance. Climate and Development, 3(3):175-192.

DOI: https://doi.org/10.1080/17565529.2011.599550 


\title{
New and additional to what? Options for baselines to assess "new and additional" climate finance
}

\author{
Martin Stadelmann ${ }^{*}$ J. Timmons Roberts ${ }^{+}$, Axel Michaelowa ${ }^{*}$
}

\begin{abstract}
All major climate policy agreements - the UN Framework Convention, the Kyoto Protocol, and recently the Cancun Agreements- have stated that climate finance for developing countries will be "new and additional". However, the term "new and additional" has never been properly defined. Agreeing a system to measure a baseline from which "new and additional" funding will be calculated will be central to building trust and realising any post-Kyoto agreement. We explore eight different options for a baseline, and assess each according to several criteria: novelty to existing pledges, additionality to development assistance, environmental effectiveness, distributional consequences, and institutional and political feasibility. Only two baseline options do well on these criteria and are therefore viable: "new sources only" and "above pre-defined business as usual level of development assistance".
\end{abstract}

Keywords: climate finance, Copenhagen Accord, development assistance, Additionality, UNFCCC

\footnotetext{
* Chair of Political Economy and Development, University of Zurich, Affolternstrasse 56, CH-8050 Zürich, Switzerland. Corresponding author: martin.stadelmann@pw.uzh.ch, tel. +41 446345091

+ Brown University, 135 Angell Street, Providence, RI 02912, USA, j_timmons_roberts@brown.edu
} 


\section{Introduction}

Since the original Stockholm Earth Summit in 1972, developing nations have feared that attention to protect the natural environment would sideline their ardent quest for meeting basic development needs like health, education and economic growth (Hicks et al., 2008, paragraph 46). Therefore, from the very beginning of international environmental statecraft, gaining these nations' cooperation in efforts to address global environmental issues required promises for funding above current development assistance ("foreign aid"). Early phrasings described "The Earth Increment", making clear that this funding would not come from other promises, such as the 1970 Monterrey pledge of most wealthy countries to send 0.7 percent of their GNI to assist poor countries overcome their poverty. The phrase "new and additional" financial resources was used at the Rio 1992 drafting of the UN Framework Convention on Climate Change (UNFCCC, 1992), and the language has appeared in every major climate agreement since, including the Kyoto Protocol (1997), the 2009 Copenhagen Accord (UNFCCC, 2009) and the Cancun Agreements (UNFCCC, 2010).

The Copenhagen Accord promises \$30 billion in "new and additional" fast-start finance" over 20102012 , "scaling up" to $\$ 100$ billion a year of public and private climate finance by 2020 . These promises, integrated in the recent Cancun Agreements, are very ambitious given the existing flows (\$ 159 billion of ODA disbursements in 2009, of which about 6 billion are marked as climate-related, see OECD (2011)). The promises were also fundamental to the reaching of any agreement given the even higher estimates for climate finance needs (e.g. \$ 150-300 billion annually by 2030 as estimated by the World Bank (2009)). Both wealthy and poor nations agree on the need for such funds: developing countries need funding to grow their economies without becoming locked in to fossil fuel dependence and its high carbon footprint. The most vulnerable developing countries also need substantial funds to prepare for, cope with, and recover from the growing number and intensity of climate-related disasters and incremental changes in local climate.

However as has happened many times before, the terms "new and additional" were never clearly defined, neither in Copenhagen nor in Cancun. "New and additional" to what exactly? Additional to what year as a baseline? Which funds get considered in such a baseline and in new funds - only those addressing climate change? Given the failure of most industrialized nations to meet their previous pledges of foreign aid, from the $19700.7 \%$ of GNI pledge to the Gleneagles 2005 promises $^{1}$, developing countries question what the term "new and additional climate finance" means in practice ${ }^{2}$. To establish clarity and potentially restore some trust in the integrity of Northern nation commitments, an agreement on the interpretation of "new and additional" is urgently needed. 
One can argue that the phrase "new and additional" has been less relevant for global environmental treaties in the past, as official financial payments for developing countries have not reached more than $\$ 0.15$ billion annually per treaty and thus the potential for diversion of large amounts of development assistance did not exist. ${ }^{3}$ This has significantly changed with Copenhagen where industrialized countries pledged $\$ 10$ billion and more per year. This raises serious questions about both compliance with these substantial pledges and their additionality to development assistance.

When defining "new and additional" climate finance, two major challenges arise. First, countries have totally different understandings of the term "new and additional" (Brown et al., 2010; Stadelmann et al., 2010; WRI, 2010). This is also reflected in the different baselines industrialized countries use for their fast-start pledges (see Table 1). Second, the assessment of "additionality" is methodologically challenging, as both realized by the Commission of Sustainable Development (Yamin and Depledge, 2004, p. 277) and scholars (Dutschke and Michaelowa, 2006).

[Table 1, includes the following sources: WRI (2010); and Faststartfinance.org (2011)]

In this article we address both challenges, the varying baseline definitions of different parties and the methodological challenges: First, the criteria for assessing baselines are discussed. Second, a series of options for baselines are analysed and assessed using five criteria (novelty to existing pledges, additionality to development assistance, effectiveness, distributional consequences, and institutional feasibility). We also examine the practical implications of these baseline proposals, and estimate political resistance and support for each of them.

\section{Criteria for a baseline}

A baseline can be defined as the level against which a commitment or action is measured. In the 1997 Kyoto Protocol, for example, Annex 1 countries pledged to reduce their emissions by certain percentages below a 1990 baseline. That very clear fixed baseline might be contrasted to a hypothetical counterfactual that describes a business-as-usual (BAU) situation, where the effect of a policy measure is assessed against what would have happened without it. These kinds of pledges of reductions in emissions below BAU projections were offered by major developing nations such as India and China in the annexes to the Copenhagen Accord and Cancun Agreements. In the context of "new and additional" climate finance, the baseline seems to logically mean the finance volume that would have flowed to developing countries in the absence of climate finance flows. The question is now how to define this business-as-usual level ${ }^{4}$. 
Our criteria used here are derived from the climate negotiation texts and the academic literature. The two obvious criteria for setting climate finance baselines are additionality and novelty, as these are the criteria climate finance has to fulfil according to various international climate agreements (UNFCCC, 1992, 1997, 2008, 2009, 2010). Furthermore, baselines can be assessed according to the four criteria for climate policies set out by the $4^{\text {th }}$ Assessment Report of the IPCC (Gupta et al., 2007): environmental effectiveness, cost-effectiveness, distributional considerations and institutional feasibility. These four criteria represent five important disciplinary views: the one of environmental sciences (environmental effectiveness), economics (cost-effectiveness), philosophy/sociology (equity) and political science (institutional feasibility/realism). The four criteria also incorporate the principles of the UNFCCC (1992): environmental effectiveness incorporates the precautionary principle spelled out in the phrase "preventing dangerous climate change"; equity incorporates the "common but differentiated responsibilities and capabilities" principle, as well as the specific needs and circumstances of developing countries; cost-effectiveness incorporates the view that climate change measures should not hinder sustainable development, and language on taking "cost effective" actions is found throughout two decades of climate agreements. While institutional feasibility is not representing any UNFCCC principle, it is clear that baselines, which fulfil all other criteria, need also political acceptability and institutions to ever be implemented. The importance and definition of each of these criteria is explained in the following.

\section{Criterion 1: Additionality to development assistance}

The discussion about development assistance baselines began essentially with the pledge of "new and additional" resources in Rio 1992. The Commission on Sustainable Development unsuccessfully tried to establish an indicator for "new and additional" financial resources in 1995 (Yamin and Depledge, 2004, p. 277). The question was further taken up in the discussion on "diversion" of development assistance in the context of CDM projects from 2000 onwards (Asuka, 2000; Dutschke and Michaelowa, 2006). Apparently, the lessons from this debate did not inform the discussion about climate finance that has taken off since 2007. Here "additionality" is an often used term but its meaning has never been clearly defined. Some understand "additional" as "additional to existing aid flows", while most developing countries and NGOs understand it as additional to existing developed country promises to provide $0.7 \%$ of their GNI as "official development assistance" (ODA) (Dutschke and Michaelowa, 2006; Oxfam, 2009; Müller et al., 2010). We use a middle-ground definition: climate finance is additional if it leads to an increase both compared to present and projected future development assistance (DA), while DA does not include the climate finance part of ODA. Climate finance may be counted as ODA but the development assistance (DA) part of ODA ${ }^{5}$ is not allowed to be reduced below "business-as-usual" projections. This is a theoretically clear definition but international institutions as well as recipients may find it difficult to assess the "business-as-usual" 
(BAU) levels of DA. Donors may have some incentives to not reveal the real BAU level of DA, similar to the distortion of investment parameters by project owners in the context of CDM projects.

\section{Criterion 2: Novelty to existing flows and pledges}

According to Müller et al. (2010) "new" mainly refers "to funds which are separate from those that have already been promised, for climate change or as overseas development assistance". However, novelty" is also increasingly understood as new funding sources such as a tax on financial market transactions, auctioning of emission allowances or levies on air and maritime transport (Müller et al., 2010). The idea behind defining novelty as "new sources" is that industrialized countries' government budgets, especially the part dedicated for developing countries, are always subject to domestic pressures (Fischer and Easterley, 1990; Bulír and Hamann, 2008; Doornbosch and Knight, 2008). Therefore, governmental funds for climate finance can always be funds that had already been pledged in the past, or promised as development assistance; and funds are only then really "new" if they stem from new sources other than government pledges. While the "new sources" definition clearly has its merits we define "new climate funds here as funds that have not yet been promised for supporting developing countries' climate or development actions, following the most common understanding according to Müller et al. (2010).

\section{Criterion 3: Environmental effectiveness}

The IPCC (Gupta et al., 2007) lists environmental effectiveness as the first criterion to evaluate environmental policies. Environmental effectiveness is understood here as the level of climate change mitigation and adaptation achieved ${ }^{6}$. Assuming that an increase in funds leads to an increase in mitigation and/or adaptation ${ }^{7}$, a baseline is environmentally effective if it increases funds useable for climate mitigation and adaptation compared to business as usual. On one hand, we can assume that the more stringent a baseline is regarding novelty to existing climate funds, the more climate funds will be paid. However, once the sum of the baseline and the new climate funds reaches the maximum level of climate finance donors are willing to pay in order to meet international standards, a further strengthening of the baseline will not increase funding or even lead to decrease. On the other hand, decreasing the stringency for additionality to existing development funds may also enhance climate funds as lenient development baselines make diversion to climate funds more probable. However, this diversion of funds through lowering development baselines will only happen until a minimum level of development assistance is reached, beyond which donors do not want to reduce further.

This theoretical view that stringent development baselines do rather decrease climate funds, is not confirmed when regressing the level of allocated fast-start funds (per GNI) on the baseline stringency level: countries with stringent baselines pay more fast-start funds, which, however, is not statistically significant when controlling for the level of ODA per GNI (see Table 1 for the data and Annex 1 for 
the regression analysis). Our theoretical argument of diversion may, however, still be relevant: currently, some climate- and development-friendly nations (e.g. Sweden, Netherlands, Norway) both have stringent baselines and high level of fast-start. An international strengthening of development baseline could make contributing nations more willing to disburse development rather than climate funds..

A criterion linked to environmental effectiveness is "cost-effectiveness": how many environmental benefits can be created by one unit of finance. We exclude this criterion in the following, as the influence of the baseline definition on cost-effectiveness is difficult to judge, for two reasons: First, the way a baseline is set does not influence how the funds are spent. Second, a baseline leveraging more funds can have different impacts: scale and learning effects linked to the size of the programmes may increase cost-effectiveness, while the exhaustion of cheap options can decrease it.

\section{Criterion 4: Distributional considerations}

As with any economic policy measure, climate policy measures will have distributional impacts. For this reason, commonly used terms in the climate policy context are "equity" and "fairness", while responsibility, capability and needs are the accepted principles for equity (Ringius et al., 2002). Distributional considerations have focused on the phrase "fair burden sharing" (see e.g. Müller et al., 2009). In our study we consider distributional questions by assessing the impact of different baselines on burden sharing between developed and developing countries. We assume that current climate policy pledges (mitigation and finance) of developed countries are way below their fair share of the burden, when considering various burden sharing studies ${ }^{8}$ (Pan, 2003; Den Elzen et al., 2005; Bernard et al., 2006; Baer et al., 2007; Marklund and Samakovlis, 2007; Den Elzen and Höhne, 2008; Chakravarty et al., 2009). A baseline, therefore, adequately addresses distribution the more it shifts the burden away from developing nations, least responsible for the problem and least capable to adapt.

\section{Criterion 5: Institutional feasibility}

The last IPCC criterion for environmental policy is institutional feasibility, or broadly speaking the question of whether the theoretical ideas can be implemented, given the existing institutions and political considerations, internationally as well as nationally. We divide institutional feasibility into four sub-criteria: a proposed method's political acceptability, its feasibility under budget constraints, its transparency, and whether it interferes with other international regimes.

\section{Criterion 5a: Political acceptability (North-South)}

Not even the most objective definition of a baseline will be feasible if it is not accepted by the major Parties to the UNFCCC. Political acceptability is an important precondition for participation, a key 
criterion for success of an environmental regime (see e.g. Wettestad, 1999). Participation is a widespread concern for the climate regime after the US did not ratify Kyoto (Barrett and Stavins, 2003); thus the impact of future non-participation has been studied as well (Keppo and Rao, 2007; van Vuuren et al., 2009). As the world's $\mathrm{CO}_{2}$ emissions are about even split between developed and developing countries (PBL, 2009; Olivier and Peters, 2010), while the share of developing countries' emissions will further rise in the future (van Vuuren et al., 2009), the acceptability for both Northern as well as Southern countries has to be assured. Under a universal international climate treaty, horse trading of climate finance and mitigation targets would be possible, which would allow one to bring baseline stringency in as one parameter of negotiations. However, the lack of progress in international climate negotiations makes the fragmentation of the regime more and more likely and thus reduces horse trading options. Furthermore, the room for concessions is narrow at the moment, as the North is dealing with the consequences of a major economic crisis and the South is harbouring mistrust due to disappointments on finance pledges ${ }^{9}$. Therefore, political acceptability of baseline stringency as part of the climate finance negotiations is a major criterion; a baseline will be politically feasible if it is expected to be acceptable to the major Parties to the UN framework convention.

\section{Criterion 5b: Feasibility under a budget constraint}

Even if the industrialized countries accept a certain baseline definition, it is not clear if it can really leverage additional climate funds without diverting development assistance. In the short-term, a government faces a certain budget constraint, given its expenditures and income. Additional finance for climate change can only be raised if government deficits are increased or if expenditures are internally shifted. As governments will hardly increase deficits in case of low-key issues such as climate finance, the most probable source of climate finance is diverted development assistance. In the mid-term, government budgets may be less constrained but aid budgets have been heavily determined by external influences such as the global economic situation and unique historic events such as the end of the Cold War (see e.g. Round and Odedokun, 2004; Mold et al., 2009). Therefore, the budget constraint is a proxy assumption for the situation a Northern government faces, which will enable us to identify some drawbacks of baseline options.

For a government with a budget constraint, the situation is depicted in Figure 1. The current and future development assistance level does not exhaust the budget, but is seen as politically optimal. We assume that the government willingness to spend "additional" climate finance is the residual of the budget constraint. In the case of a baseline less stringent than BAU development assistance, the government will increase climate finance at the expense of development assistance as far as the baseline permits ${ }^{10}$, due to the preferences of the electorate to embark on climate policy. In the case of 
a baseline that is more stringent than BAU of development assistance, the country increases development assistance spending beyond the current level until the entire budget is spent, in order to be able to generate "new and additional climate funds." If the baseline stringency goes beyond the budget constraint, then the country cannot spend anything on "additional" climate finance and development assistance spending abruptly decreases to the BAU level. Therefore, the only feasible baselines under a budget constraint are the ones between the projected BAU level of development assistance and the budget constraint.

\section{[Figure 1]}

Criterion 5c: Transparency: clarity of definition and availability of data.

The importance of transparency for environmental regimes is acknowledged by academic scholars, governments and NGOs (Mitchell, 1998). Transparency helps for achieving and assessing compliance and effectiveness, which has been studied both for security and environmental regimes (Mitchell, 1998; Roberts and Parks, 2007). Transparency is important in many ways for the climate regime: e.g. related to greenhouse gas inventories or the negotiation process ${ }^{11}$. Regarding transparency of finance, financial contributions have haphazardly been included in national communications, but transparency only came to the forefront when the notion of "nationally appropriate mitigation actions [...] supported and enabled by technology, financing and capacity-building, in a measurable, reportable and verifiable manner" was included in the Bali Action Plan (UNFCCC, 2008). By this wording, not only the actions of developing but also the financial support of developed countries was to be measured and verified. While the Parties are still negotiating the way this has to be done, scholars have already identified the need for more transparency: the new climate funds set up in the last few years lack transparency (Stewart et al., 2009) and more transparent guidelines for finance reporting are needed under the UNFCCC (Roberts et al., 2010a; Tirpak et al., 2010). Such guidelines seem especially important as the current way of labelling ODA as climate-related (labelling by donors using the OECD's Rio Markers) has been inconsistent and politically-driven in the past (Michaelowa and Michaelowa, 2010) ${ }^{12}$.

The transparency of a baseline is given if international organizations or parties can easily assess whether the baseline for climate finance has been complied with. This assessment is possible if two conditions are met: first, the definition of a baseline must be clear to avoid renegotiation and redefinition. Second, the data for measurement and verification must be accessible and assessable. Therefore, we will assess the transparency of baseline definitions by both analysing the clarity of the definition and the availability of data. 


\section{Criterion 5d: Consistency with other regimes}

Rules within the climate change regime may not be consistent with well established rules of other regimes. This has especially been studied for the case of border carbon adjustment and the trade regime (see e.g. Charnovitz, 2003; Brewer, 2004; Biermann and Brohm, 2005): e.g. taxes on embodied carbon in imported goods, which can be seen as contributing to the precautionary principle within the climate regime, are not consistent with WTO principles on free trade. In the case of climate finance, we may have some interference with the rules for accounting development assistance. The wording of "new and additional" in the climate regime somehow calls for a separation of development and climate funds. However, the Organization of Economic Co-operation and Development (OECD) has established rules that all financial transfers with a certain level of concessionality qualify as Official Development Assistance (ODA). Therefore, a decision to not count climate funds as ODA would heavily interfere with the established OECD rule, which is backed by major donor

preferences ${ }^{13}$. Beside the definition of ODA, a baseline definition may also include assumptions on the pledged level of ODA, which is a large intervention into the development assistance regime as well, given that donors are used to having sovereignty on ODA commitments. In contrast, honing the definition of climate finance is less interfering into the development regime, as the existing Rio Markers for both mitigation and adaptation (OECD, 2009) are quite new, not defined in detail, and the definition is sometimes poorly understood by donor staff $\mathrm{f}^{14}$. Therefore, we define the consistency with other regimes as the level of consistency of climate regime rules with well-established rules in the development assistance regime. Major interferences would be a change of the ODA definition or fixing the level of ODA commitments.

\section{Options for a baseline}

In this section we describe eight baseline options and assess how well they perform on the criteria just listed. Seven of the analysed baseline options are the ones mentioned in the literature and the negotiations: $0.7 \%$ of GNI, no baseline, new channels, no ODA counts, current climate finance, current development assistance and new sources. Furthermore, we propose a new, potentially promising definition: projected development assistance.

\section{Option 1: $0.7 \%$ of GNI}

Many developing countries prefer that the ticker for new and additional funding start only after countries have contributed $0.7 \%$ of their gross national income (GNI) to ODA (Ballesteros and Moncel, 2010). The target that developed countries provide $0.7 \%$ of their Gross National Income (GNI) as ODA has first been mentioned in the Report of the Commission on International Development (Pearson, 1969), without any clear explanation on how this has been calculated 
(Clemens and Moss, 2005). The 0.7\% target has been several time restated, e.g. at the "Earth Summit" in Rio de Janeiro 1992 and importantly in the final declaration of the UN's International Conference on Financing for Development in Monterrey 2002, attended by many heads of state (Clemens and Moss, 2005) ${ }^{15}$. Until now, the $0.7 \%$ has been reached by only a very small number of countries, and the highest overall ratio of ODA to GNI has been achieved before the target was even set (see Figure 2). The $0.7 \%$ GNI threshold is also a favourite of European countries like Norway and the Netherlands that already meet this ODA standard.

Although this threshold seems transparent and takes into account past pledges by developed countries, it is not viable for two reasons. First, many developed countries will in the next few years neither accept nor reach this threshold—especially the United States, with less than $0.2 \%$ of its GNI going to ODA. Or in other words, the option is not feasible under the budget constraint of some countries and, as the barrier is too high, some countries may even tend to pay less climate funds, which would lower environmental effectiveness. Second, countries like Sweden and Denmark, which today exceed the $0.7 \%$ mark, may just divert existing ODA commitments and call them new and additional climate finance. The non-feasibility of the $0.7 \%$ threshold has already been explained by Dutschke \& Michaelowa (2006) for the case of the CDM.

\section{[Figure 2]}

\section{Option 2: No agreed baseline}

Most industrialized countries favour having no agreed baseline, so that each contributor defines its own baseline. This option is clearly not acceptable for developing countries, and "additionality to development assistance is not given. Furthermore, the definitions will be arbitrary, comparing funding across nations becomes very difficult, transparency is hardly given, and diversion of development assistance is likely. This option is the current state of affairs at this writing, as each donor has its own (or even no) definition of the baseline (WRI, 2011)

\section{Option 3: New UN channels only}

A simple option for avoiding this situation with unclear baselines is to count only funding disbursed through new channels, such as the Adaptation Fund or the planned Green Climate Fund. Although technically clear, the "new channels only" approach reduces flexibility for contributors and makes it less acceptable to them to use the term "new and additional" or leaves them less willing to disburse climate funds. Some existing channels may be better suited for certain types of flows or certain efforts 
to address climate change.. This approach could have absurd consequences if old commitments are simply redirected into new funds.

\section{Option 4: No ODA counts}

Another straightforward option would allow using the best channels and mechanisms, but would not count ODA money as climate finance, to clearly separate between development and climate funds. This options is favoured by many developing countries, who want climate finance to be above ODA (Ballesteros and Moncel, 2010). Double-counting could be avoided and transparency enhanced. Additional administrative costs of separately accounting climate funds from ODA are minimal if built on existing accounting systems ${ }^{16}$. This approach forces contributors to decide whether the main goal of funding is development or climate related. Despite the advantages of this approach, it is rejected by most industrialized countries, as they prefer to use climate funds to reach their ODA targets.

Furthermore, developing countries argue that climate change issues should be "mainstreamed" into existing development assistance, which is a non-consistent argument for rejecting separate accounting: While mainstreaming in itself may be important ${ }^{17}$, it is not constrained by separate accounting of development and climate funds ${ }^{18}$. Furthermore, this baseline approach would be inconsistent with the well established rule in the development assistance regime that all concessional flows can be counted as $\mathrm{ODA}^{19}$.

\section{Option 5: Current climate finance}

A baseline acceptable to contributors (and according to Brown et al. (2010) supported by Germany) may be current climate finance: the existing climate funds and those pledged before Copenhagen would define the fixed baseline. This could be the final year before Copenhagen (2008 or 2009), or a five-year average such as 2005-2009. On the downside, with this model the diversion of developmentoriented aid is possible, and information on current climate finance is scarce. In three analyses, we have attempted to quantify current levels of climate finance (Roberts et al., 2008; Michaelowa and Michaelowa, 2010; Roberts et al., 2010b). Many definitional problems arise, showing starkly conflicting numbers between OECD "Rio Marker" totals and those of our independent categorizations at the project level. Therefore, the criterion of transparency is currently not given, both in terms of clarity of definition and availability of data. However with clear definitions and sufficient resources, such a baseline could be constructed for major contributor nations in the future.

\section{Option 6: Current development assistance}

Very close to current climate finance is the idea of a baseline of current development assistance. In this case, all contributions above current development assistance may count as climate finance. Two contributor countries, Australia and Switzerland, use a similar definition to this when saying that their fast track pledge is part of an increase in development assistance (WRI, 2010). This essentially means 
that all climate finance can be called "new and additional" as long as the development part of ODA is increasing. However, this definition has some fundamental flaws: ODA has been increasing over time and is expected to increase even more in the future as most countries attempt to get closer to their $0.7 \%$ of GNI target or their Gleneagles 2005 promises. Australia and Switzerland both fit this pattern: their ODA has increased in the last few years, they have not yet met the $0.7 \%$ target, and it can be projected that their ODA will increase in the future (see Figure 3Figure 3). This baseline will, therefore, not fulfil the criterion of "additionality to development assistance" and will not be acceptable for developing countries.

\section{[Figure 3, includes sources from OECD (2010) and WB (2010)]}

\section{Option 7a: Updated projections of development assistance}

Instead of current development assistance levels, updated projections of development assistance could be used as a baseline, which is a new option we propose (although Huhtala et al. (2010) mean a similar baseline when proposing "benchmarking"). In this case, business-as-usual funding levels would be reassessed every year or two, taking into account current economic growth in industrialized countries and development assistance commitments. For example, country X plans to increase development assistance to $\$ \mathrm{x}$ billion per 2020 if its economy is steadily growing. However, an economic crisis just before 2015 makes the reaching of this target impossible. Therefore, the country will lower its projected baseline for 2020 and the international community may allow the country to lower its baseline for 2015. This option may be acceptable to contributors, as it could allow future spending on climate finance to fall somewhat during economic downturns. Of course, obligations would also increase in strong growth years. Although this method is theoretically close to the perfect assessment of "new and additional", it might fail at creating trust between parties, as developed countries may be suspected of gaming the baseline, and because baselines are renegotiated every few years. Therefore, we judge this baseline to not fulfil the criteria of "clarity of definition" and "political acceptability in the South".

\section{Option 7b: Pre-defined projection of development assistance (with GNI growth adjustment)}

A variant baseline using pre-defined projections of development assistance would avoid this permanent re-negotiation by defining the projected business-as-usual level of development assistance in advance, according to a realistic growth path for development assistance. The pre-definition task would create a debate on which development assistance growth path is most realistic-very recent years or a longer-term trend ${ }^{20}$. Industrialized countries may be concerned about agreeing to specific 
levels of development assistance and climate finance without knowing their future GNI growth and related tax income. It is relatively straightforward, however, to use a formula that takes into account real GDP growth in later years ${ }^{21}$ (see Figure 4 for illustration). The GNI dependence of the funds would be a downside for developing countries, but by avoiding re-negotiation of the formula they would benefit from better predictability. We do not see any major drawbacks beside some interference with the development assistance regime ${ }^{22}$.

\section{[Figure 4]}

\section{Option 8: New sources only}

A final baseline definition, also proposed by Huhtala et al. (2010) for defining "new", is "new sources only", which is actually an alternative definition to "novelty" we rejected earlier. It combines all issues: novelty, additionality and acceptability. This baseline would count new sources only, meaning that only assistance from novel funding sources—-such as international air transport levies, currency trading levies or auctioning of emission allowances-would be seen as new and additional. Such funds are new by definition, and they are likely to be additional to development assistance, as it is highly improbable that new funding instruments—especially the ones related to pricing carbon emissions would be used for development assistance without a climate policy regime. The obvious drawbacks are that it inflexibly bars the use of effective current funding streams, and would somewhat arbitrarily define which sources are new. Although we believe that this baseline could be acceptable for contributors, they have ruled it out for 2010-2012 "fast-start" financing, which will draw on existing sources such as the general budget. Therefore, the "new sources only" option is probably one for longer-term (post-2012) climate finance, especially the ramping up of climate finance for the 2020 promise of $\$ 100$ billion a year, for which the UN Secretary-General's High-level Advisory Group on Climate Change Financing is suggesting especially new sources such as carbon taxes, auctioning of emission allowances or levies on international transport (UN, 2010).

\section{Summary of options}

When assessing the different baseline options with the criteria discussed (Table 1) most options do not fulfil at least one criterion. Only the baseline options "above a pre-defined projection of development assistance with GDP growth adjustment" and "new sources only" can guarantee some level of additionality, novelty, and acceptability by parties, as well as transparency and consistency with other regimes. 
The option "pre-defined projection of development assistance with GDP growth adjustment" does not perform very well on any particular criterion, but it also lacks any major drawbacks. The main challenge is to predefine projections of the development part of ODA. Such projections would not mean a change of existing regime rules but to introduce a new rule, which will have to be agreed at the head of state level. The second option with no negative rating on any criterion is "new sources only," which we consider very promising given that there is international agreement that new sources are needed. Both the Copenhagen Accord and the Cancun Agreements specify that "alternative sources of finance" are to be included, but do not provide specific suggestions, which shows that a component of a baseline has to come from new sources. While the "new sources" baseline option may have, therefore, political support, it is hardly feasible in a strict sense: totally refraining from using traditional aid budgets will decrease flexibility on the donor side and may, therefore, limit both acceptability in the North and lower the overall climate funds (and, therefore, environmental effectiveness)., Furthermore, many developing countries wish that most funding is coming from public sources (see e.g. IISD, 2010a), whereas "new sources" also include private funds. Therefore, a less strict baseline, e.g. the use of "at least $50 \%$ new sources" may be more promising.

\section{[Table 2]}

\section{Conclusions}

The current state of no transparency on novelty and additionality of climate finance pledges will perpetuate mistrust in the climate regime. Many options for a baseline for a definition what "new and additional" means have been put forward but the parties to the UNFCCC have not yet agreed on any. From the climate negotiation texts and the academic literature we derive that a meaningful and successful baseline must at least fulfil the following criteria: novelty, additionality, equity, acceptability, transparency and consistency with other regimes. We conclude that only two of the assessed baseline options are not violating any criterion excessively: "Above pre-defined projection of development assistance" and "new sources only". It is, therefore, warranted that parties consider those two baseline options instead of restating their old extreme positions of either no baseline or a threshold of $0.7 \%$ of GNI going to ODA.

Procedurally, the discussion on a baseline should be included either in the Ad-hoc Working Group on Long-term Cooperative Action under the Convention, or as subtask for the new Standing Committee on Climate Finance. If a global agreement on a single baseline definition is not possible, a (distant) second-best solution would be to oblige each contributor to transparently declare its own baseline 
definition, while providing guidance on needed data for each baseline option. Both a common as well as individual baselines could be part of the "enhanced common reporting methodologies for finance and tracking of climate-related support", for which modalities and guidelines should be developed according to the Cancun Agreements (UNFCCC, 2010, paragraph 46).

Both industrialized and developing countries can do their part to reach a compromise: while industrialized countries could agree on elaboration of an internationally defined baseline or at least attach a baseline to each of their pledges, developing countries may acknowledge that it was almost impossible for industrialized countries to contribute \$ 10 billion of "new and additional" funding in 2010, as the 2010 budgets have mostly been determined before Copenhagen. More scrutiny may be applied to the figures for 2011 and 2012. Meanwhile, the "scaling up" period from 2013 (when faststart finance is past) and 2020 (when $\$ 100$ billion/year is pledged) requires a sharp increase of about $\$ 10$ billion/year: deciding a baseline is critical for financing action during this period.

In the end, defining a baseline for "new and additional" is just one of many important pieces in the larger jigsaw of climate finance. The new Transitional Committee will have to design the detailed governance structures and modalities for access for the Green Climate Fund. However, this new fund will only be part of the various bilateral, multilateral, private and even South-South flows that have to do with financing climate change mitigation and adaptation. For realising the full potential of climate finance, parties to the UNFCCC have to decide on a definition of "climate finance" and on rules and institutions on how to track it. In parallel, new and acceptable financing sources have to be identified. The new Standing Committee on Climate Finance could deliver important preparatory work for decisions on definitions (both climate finance and "baselines"), tracking modalities and new sources.

\section{Acknowledgements}

We would like to thank Saleemul Huq, Benito Müller, researchers at the World Resources Institute and two anonymous reviewers for comments on an earlier version.

\footnotetext{
Notes

${ }^{2}$ Donors were never before as specific as at the Gleneagles summit: the European G8 members pledged to increase their ODA to $0.7 \%$ of their GNI by 2012-2015, while also the US, Canada and Japan made pledges for substantial increase of their ODA (G8, 2005).

${ }^{2}$ For the uncertainty about delivery of Copenhagen finance promises and needed transparency, see Rudyk (2009) and Schalatek et al. (2010)
} 
${ }^{3}$ It has to be noted that these pledges were much smaller than the $\$ 125$ billion of annual international grants or concessional flows needed to implement the Agenda 21 activities as estimated in 1992 (UNDESA, 1992), which never materialized. However, compliance with the low pledges for biodiversity, climate change and ozone has been high (see Benedick, 1998; GEF, 2006; Pallemaerts and Armstrong, 2009; GEF, 2010; UNEP, 2010).

${ }^{4}$ Substantial experience of how to define baselines has been collected in the context of climate change mitigation in developing countries financed through the CDM, see (see Michaelowa et al., 2007).

${ }^{5}$ Official Development Assistance (ODA) as defined by the OECD-DAC currently consists of developmentfocused programs but also of other funds such as for global environmental goods (e.g. Multilateral Fund in the ozone regime or climate change mitigation funds). When using the concept of "development assistance" (DA), we want to make clear that we only refer to ODA funds for "development" and not to ODA funds for "climate". This distinction is similar to the distinction between "ODA classic" and "ODA climate", as made by Huhtala et al. (2010).

${ }^{6}$ Strictly speaking, only mitigation has an "environmental" impact by reducing climate change, while adaptation has mainly direct economic benefits. However, as most climate finance is used for mitigation, we can easily assume that climate finance enhances environmental effectiveness.

${ }^{7}$ This is a weak assumption in our view: if international mechanisms are stringent enough, climate funds will be spent on climate-related activities. Assuming minimal knowledge on mitigation and adaptation, environmental benefits per unit may decrease with increased finance but will stay positive. In few cases, climate funding may actually decrease environmental effectiveness, e.g. in case of maladaptation or if funds are allocated to energy efficient coal power plants, which would have been built anyway. However, it is highly probable that such negative effects will not outweigh the positive effects of climate finance.

${ }^{8}$ Also advanced developing countries such as China, South Korea or Mexico may have to contribute. However, the bulk of climate finance will have to come from industrialized countries.

${ }^{9}$ For a recent critique of India and South Africa that industrialized countries do not deliver promised climate finance, see Jebaraj (2011)

${ }^{10}$ While diversion of a planned increase in development assistance is probable, we may hardly see a decrease in the current level of DA funding.

${ }^{11}$ See e.g. the Cancun summit: the success was partly related to the transparent procedures, applauded by many parties (IISD, 2010b).

${ }^{12}$ The Rio Markers are an important attempt to bring more transparency but the labeling has to be improved or replaced by a new system in order to fulfill the function of transparency.

${ }^{13}$ A senior Northern government official reported that his country advocated the change of the ODA definition in order to separate climate funding. The attempt, however, had no chances.

${ }^{14}$ This also points to the idea that climate finance labelling may be improved by training donors in reporting Rio markers.

${ }^{15}$ In contrast to the public perception, industrialized countries actually for a long time never promised to reach the $0.7 \%$ target but only to make efforts to attain it (Clemens and Moss, 2005). This changed when the EU pledged that their old member states reach the $0.7 \%$ level by 2015 (EU, 2005).

${ }^{16}$ For e.g. the only change to the existing OECD DAC system would be that funds marked with the climate change Rio Marker would not be counted as ODA but reported as "climate finance". However, the quality of the Rio Markers needs to be improved, see footnote 12.

${ }^{17}$ The mainstreaming is important for making sure that climate change issues are integrated into development planning. It is, however, questionable if climate change mitigation would strengthen development as mitigation projects contribute to the Millennium Development Goals only to a minor extent (see Michaelowa and Michaelowa, 2007).

${ }^{18}$ Separate accounting just means that in case of a larger development project, in which climate change concerns are mainstreamed, donors have to decide which part of the funding is development-related (ODA) and which part is climate finance. This accounting exercise does not have an impact on the project design at all.

${ }^{19} \mathrm{~A}$ softened version of this option is the idea of former British Prime Minister Gordon Brown to limit the climate finance that can be accounted as ODA to $10 \%$ of overall ODA contribution. All climate finance beyond this $10 \%$ needs to come from other sources to be seen as "new and additional" (Brown et al., 2010). We do not treat this as a separate option here, as the $10 \%$ seems to be an artificial number that made sense for the UK Prime Minister at a given time. We never heard that this number has been repeated by other nations.

${ }^{20}$ For example in Figure 3 Switzerland shows a steeper increase over the final three years than over the trendAustralia's ODA was flat and then dropped in 2009, but a longer-term trend since 1996 gives it the steepest slope of the three.

${ }^{21}$ This pre-definition with later adjustment is similar to the case of the Clean Development Mechanism where the baseline is estimated before the project is registered but it is adjusted ex-post according to some predefined formula (e.g. the production level or the units installed). 
${ }^{22}$ This interference is not very severe, since projections of development assistance do not actually impact the definition of ODA, as we distinguish here between ODA (all funds counted as Official Development Assistance including climate finance) and development assistance (development funds only; excluding climate finance). Introducing a new measure such as DA is less conflicting with existing rules than changing the existing definition of ODA. 


\section{Literature}

Asuka, J., 2000. ODA baseline as a criterion for financial additionality. Joint Implementation Quarterly 6 (3). 9.

Baer, P., Athanasiou, T. and Kartha, S., 2007. The Right to Development in a Climate Constrained World. The greenhouse development rights framework. Heinrich Böll Foundation, Christian Aid, EcoEquity and the Stockholm Environment Institute, Berlin.

Ballesteros, A. and Moncel, R., 2010. Additionality of Climate Finance. World Resources Institute, Washington D.C.

Barrett, S. and Stavins, R., 2003. Increasing Participation and Compliance in International Climate Change Agreements. International Environmental Agreements: Politics, Law and Economics, 3(4). 349-76.

Benedick, R.E., 1998. Ozone diplomacy : new directions in safeguarding the planet. Harvard University Press, Cambridge, MA, USA.

Bernard, A., Vielle, M. and Viguier, L., 2006. Burden sharing within a multi-gas strategy. Energy Journal. 289-304.

Biermann, F. and Brohm, R., 2005. Implementing the Kyoto Protocol without the USA: the strategic role of energy tax adjustments at the border. Climate Policy, 4(3). 289-302.

Brewer, T.L., 2004. The WTO and the Kyoto protocol: interaction issues. Climate Policy, 4(1). 3-12.

Brown, J., Bird, N. and Schalatek, L., 2010. Climate finance additionality: emerging definitions and their implications. Climate Finance Policy Brief No.2. Heinrich Böll Stiftung North America / Oversea Development Institute, Washington D.C. / London.

Bulír, A. and Hamann, A.J., 2008. Volatility of Development assistance: From the Frying Pan into the Fire? World Development, 36(10). 2048-66.

Chakravarty, S., Chikkatur, A., de Coninck, H., Pacala, S., Socolow, R. and Tavoni, M., 2009. Sharing global $\mathrm{CO} 2$ emission reductions among one billion high emitters. Proceedings of the National Academy of Sciences of the United States of America, 106(29). 11884-88. doi:10.1073/pnas.0905232106.

Charnovitz, S., 2003. Trade and climate: Potential conflicts and synergies. Working Draft. Pew Center on Global Climate Change, Arlington.

Clemens, M.A. and Moss, T.J., 2005. Ghost of 0.7\%: Origins and Relevance of the International Aid Target. Working Paper \# 68. Center for Global Development, Washington D.C.

Den Elzen, M. and Höhne, N., 2008. Reductions of greenhouse gas emissions in Annex I and non-Annex I countries for meeting concentration stabilisation targets. Climatic Change, 91(3-4). 249-74.

Den Elzen, M., Schaeffer, M. and Lucas, P.L., 2005. Differentiating future commitments on the basis of countries' relative historical responsibility for climate change: Uncertainties in the 'Brazilian proposal' in the context of a policy implementation. Climatic Change, 71(3). 277-301. doi:10.1007/s10584-005-5382-9.

Doornbosch, R. and Knight, E., 2008. What role for public finance in international climate change mitigation. Discussion Paper. Organisation for Economic Co-operation and Development, Paris.

Dutschke, M. and Michaelowa, A., 2006. Development assistance and the CDM - how to interpret 'financial additionality'. Environment and Development Economics, 11. 235-46. doi:10.1017/S1355770x05002780.

EU, C.o.t., 2005. Council conclusions: Accelerating progress towards achieving the millenium development goals. Council of the European Union. External Relations Council, Brussels.

Faststartfinance.org, 2011. Fast Start Finance. Contributing countries. http://www.faststartfinance.org/content/contributing-countries, accessed 26th April 2011. 
Fischer, S. and Easterley, W., 1990. The economics of the government budget constraint. The World Bank Research Observer, 5(2). 127-42.

G8, 2011. Financing commitments (as submitted by individual G8 members). Annex 2 of document "Africa". http://www.canadainternational.gc.ca/g8/assets/pdfs/g8_Africaen.pdf, accessed 20th April 2011.

GEF, 2006. Trustee Report. GEF/C.30/Inf.3, Global Environment Facility, Washington D.C.

GEF, 2010. Trustee Report. Global Environment Facility Trust Funds. As of April 30, 2010. . GEF/C.38/Inf.13, Global Environment Facility, Washington D.C.

Gupta, S., Tirpak, D., Burger, N., Gupta, J., Höhne, N., Boncheva, A., Kanoan, G., Kolstad, C., Kruger, J., Michaelowa, A., Murase, S., Pershing, J., Saijo, T. and Sari, A., 2007. Policies, Instruments and Co-operative Arrangements. Climate change 2007. Mitigation of climate change. Contribution of Working Group III to the Fourth assessment report of the Intergovernmental Panel on Climate Change, B. Metz, O. R. Davidson, P. R. Bosch, R. Dave, and L. A. Meyer (eds.). Cambridge University Press, Cambridge; New York. 745-808.

Hicks, R.L., Parks, B.C., Roberts, J.T. and Tierney, M.J., 2008. Greening aid? Understanding the environmental impact of development assistance. Oxford University Press, Oxford; New York.

Huhtala, A., Curto, S. and Ambrosi, P., 2010. Monitoring Climate Finance and ODA. Development, Climate and Finance. Issues Brief \#1, May 2010. World Bank, Washington D.C.

IISD, 2010a. Geneva Dialogue on Climate Finance Bulletin. Summary of the Geneva Dialogue on Climate Finance. 2-3 September 2010. IISD reporting services. 1, International Institute for Sustainable Development, Winnipeg.

IISD, 2010b. Summary of the Cancun Climate Change Conference. 29 November - 11 December 2010. Earth Negotiations Bulletin. 498, International Institute for Sustainable Development, Winnipeg.

Jebaraj, P., 2011. Fast start finance for climate change has not even passed double digit. The Hindu, 27th February 2011.

Keppo, I. and Rao, S., 2007. International climate regimes: Effects of delayed participation. Technological Forecasting and Social Change, 74(7). 962-79. doi:10.1016/j.techfore.2006.05.025.

Marklund, P.O. and Samakovlis, E., 2007. What is driving the EU burden-sharing agreement: Efficiency or equity? Journal of Environmental Management, 85(2). 317-29.

Michaelowa, A. and Michaelowa, K., 2007. Climate or development: is ODA diverted from its original purpose? Climatic Change, 84(1). 5-21. DOI 10.1007/s10584-007-9270-3.

Michaelowa, A. and Michaelowa, K., 2010. Coding Error or Statistical Embellishment? The Political Economy of Reporting Climate Aid. CIS Working Papers, 56/2010. Center for Comparative and International Studies (CIS), ETH Zurich and University of Zurich, Zurich.

Michaelowa, A., Gagnon-Lebrun, F., Hayashi, D., Luis, S.F., Crete, P. and Krey, M., 2007. Understanding CDM methodologies. DEFRA, London.

Mitchell, R.B., 1998. Sources of transparency: Information systems in international regimes. International Studies Quarterly, 42(1). 109-30.

Mold, A., Paulo, S. and Prizzon, A., 2009. Taking stock of the credit crunch: Implications for development finance and global governance. Working Paper No. 277. OECD Development Centre, Paris.

Müller, B., Höhne, N. and Ellermann, C., 2009. Differentiating (historic) responsibilities for climate change. Climate Policy, 9(6). 593-611. 
Müller, B., Sharma, A., Gomez-Echeverri, L., Rook, D.P. and Chandani, A., 2010. The Reformed Financial Mechanism of the UNFCCC. Part II. The Question of Oversight. Post Copenhagen Synthesis Report. OIES EV 52. Oxford Institute for Energy Studies, Oxford.

OECD, 2009. OECD Development Assistance Committee Tracks Aid in Support of Climate Change Mitigation and Adaptation. Information note. Organization of Economic Cooperation and Development, Paris.

OECD, 2010. ODA by Donor. http://stats.oecd.org/Index.aspx, accessed 31st August 2010.

OECD, 2011. OECD.StatExtracts. Creditor Reporting System_Full. http://stats.oecd.org/Index.aspx, accessed 18th March 2011.

Olivier, J.G.J. and Peters, J.A.H.W., No growth in total global CO2 emissions in 2009. accessed

Oxfam, 2010. Will the EU Backtrack or Fast-forward on Global Climate Money? Oxfam press release 9 December 2009. http://www.oxfam.org/en/pressroom/pressrelease/2009-1209/will-eu-backtrack-or-fast-forward-global-climate-money, accessed 31th August 2010.

Pallemaerts, M. and Armstrong, J., 2009. Financial Support to Developing Countries for Climate Change Mitigation and Adaptation: Is the EU Meeting its Earlier Commitments? Institute for European Environmental Policy, London.

Pan, J., 2003. Emissions Rights and their Transferability. Equity Concerns over Climate Change Mitigation. International Environmental Agreements: Politics, Law and Economics, 3(1). $1-16$.

PBL, 2009. Global CO2 emissions from fossil fuel use and cement production per region, 19902008. http://www.pbl.nl/images/c-0533-001g-mnc-04-nl_tcm61-43781.xls, accessed 20th December 2009.

Pearson, L.B., 1969. Partners in development. Report of the Commission on International Development. Praeger, New York.

Ringius, L., Torvanger, A. and Underdal, A., 2002. Burden Sharing and Fairness Principles in International Climate Policy International Environmental Agreements: Politics, Law and Economics, 2(1). 1-22.

Roberts, J.T. and Parks, B.C., 2007. A climate of injustice : global inequality, North-South politics, and climate policy. Global environmental accord. MIT Press, Cambridge, MA, USA.

Roberts, J.T., Stadelmann, M. and Huq, S., 2010a. Copenhagen's climate finance promise: six key questions. IIED briefing. International Institute for Environment and Development, London.

Roberts, J.T., Weissberger, M. and Peratsakis, C., 2010b. Trends in Official Climate Finance: Evidence from Human and Machine Coding. Aid Transparency and Development Finance Conference, 22nd - 24th March 2010, Oxford.

Roberts, J.T., Starr, K., Jones, T. and Abdel-Fattah, D., 2008. The Reality of Official Climate Aid. Oxford Energy and Environment Comment. Oxford Institute of Energy Studies, Oxford.

Round, J.I. and Odedokun, M., 2004. Aid effort and its determinants. International Review of Economics \& Finance, 13(3). 293-309.

Rudyk, B., 2011. Overcoming distrust - the need for a global climate finance registry. http://opiniojuris.org/2009/12/17/overcoming-distrust-\%E2\%80\%93-the-need-for-aglobal-climate-finance-registry/, accessed 20th April 2011.

Schalatek, L., Bird, N. and Brown, J., 2010. Where's the Money? The Status of Climate Finance Post Copenhagen. The Copenhagen Accord, UNFCCC Negotiations and a Look at the Way Forward. Heinrich Böll Stiftung North America / Oversea Development Institute, Washington D.C. / London. 
Stadelmann, M., Roberts, J.T. and Huq, S., 2010. Baseline for trust: defining 'new and additional' climate funding. IIED briefing. International Institute for Environment and Development, London.

Stewart, R.B., Kingsbury, B. and Rudyk, B., 2009. Climate Finance for Limiting Emissions and Promoting Green Development Mechanisms, Regulation, and Governance. Climate finance : regulatory and funding strategies for climate change and global development, R. B. Stewart, B. Kingsbury, and B. Rudyk (eds.). New York University Press : New York University Abu Dhabi Institute, New York. 3-34.

Tirpak, D., Ballesteros, A., Stasio, K. and McGray, H., 2010. Guidelines for Reporting Information on Climate Finance. Working Paper. World Resources Institute, Washington D.C.

UN, 2010. Report of the Secretary-General's High-level Advisory Group on Climate Change Financing. United Nations, New York.

UNDESA, 2010. Agenda 21. Section IV: Means of Implementation. Chapter 33: Financial Resources \& Mechanisms. http://www.un.org/esa/dsd/agenda21/res_agenda21_33.shtml, accessed 2nd November 2010.

UNEP, 2010. Statuts of contributions and disbursements. The Status of the Fund as at 5 March 2010. Report from the Treasurer. Executive committe of the Multilateral Fund for the implementation of the Montreal Protocol. Sixtieth Meeting, Montreal, 12-15 April 2010. United Nations Environment Programme, Nairobi.

UNFCCC, 1992. United Nations Framework Convention on Climate Change. United Nations Framework Convention on Climate Change, Bonn.

UNFCCC, 1997. Kyoto Protocol. United Nations Framework Convention on Climate Change, Bonn.

UNFCCC, 2008. Decision 1/CP.13. Bali Action Plan. Report of the Conference of the Parties on its thirteenth session, held in Bali from 3 to 15 December 2007. Addendum. Part Two: Action taken by the Conference of the Parties at its thirteenth session. United Nations Framework Convention on Climate Change, Bonn.

UNFCCC, 2009. Copenhagen Accord. Advance unedited version. United Nations Framework Convention on Climate Change, Bonn.

UNFCCC, 2010. The Cancun Agreements: Outcome of the work of the Ad Hoc Working Group on Long-term Cooperative Action under the Convention. Decision 1/CP.16. FCCC/CP/2010/7/Add.1, United Nations Framework Convention on Climate Change, Bonn.

van Vuuren, D.P., den Elzen, M.G.J., van Vliet, J., Kram, T., Lucas, P. and Isaac, M., 2009. Comparison of different climate regimes: the impact of broadening participation. Energy Policy, 37(12). 5351-62. doi: 10.1016/j.enpol.2009.07.058.

WB, 2010. World Bank Data. http://data.worldbank.org/, accessed 4th October 20102010.

Wettestad, J., 1999. Designing effective environmental regimes : the key conditions. New horizons in environmental economics. Edward Elgar, Cheltenham, UK.

WorldBank, 2009. World Development Report 2010. Development and Climate Change. World Bank, Washington D.C.

WRI, 2010. Summary of Developed Country 'Fast-Start' Climate Finance Pledges. http://www.wri.org/stories/2010/02/summary-developed-country-fast-start-climatefinance-pledges, accessed 31st August 2010.

WRI, 2011. Summary of Developed Country 'Fast-Start' Climate Finance Pledges. http://www.wri.org/publication/summary-of-developed-country-fast-start-climatefinance-pledges, accessed 26th April 2011.

Yamin, F. and Depledge, J., 2004. The international climate change regime : a guide to rules, institutions and procedures. Cambridge University Press, Cambridge; New York. 
Figure 1: Impact of baseline stringency on the level of spending for development assistance (DA) and climate finance in case of budget constraint

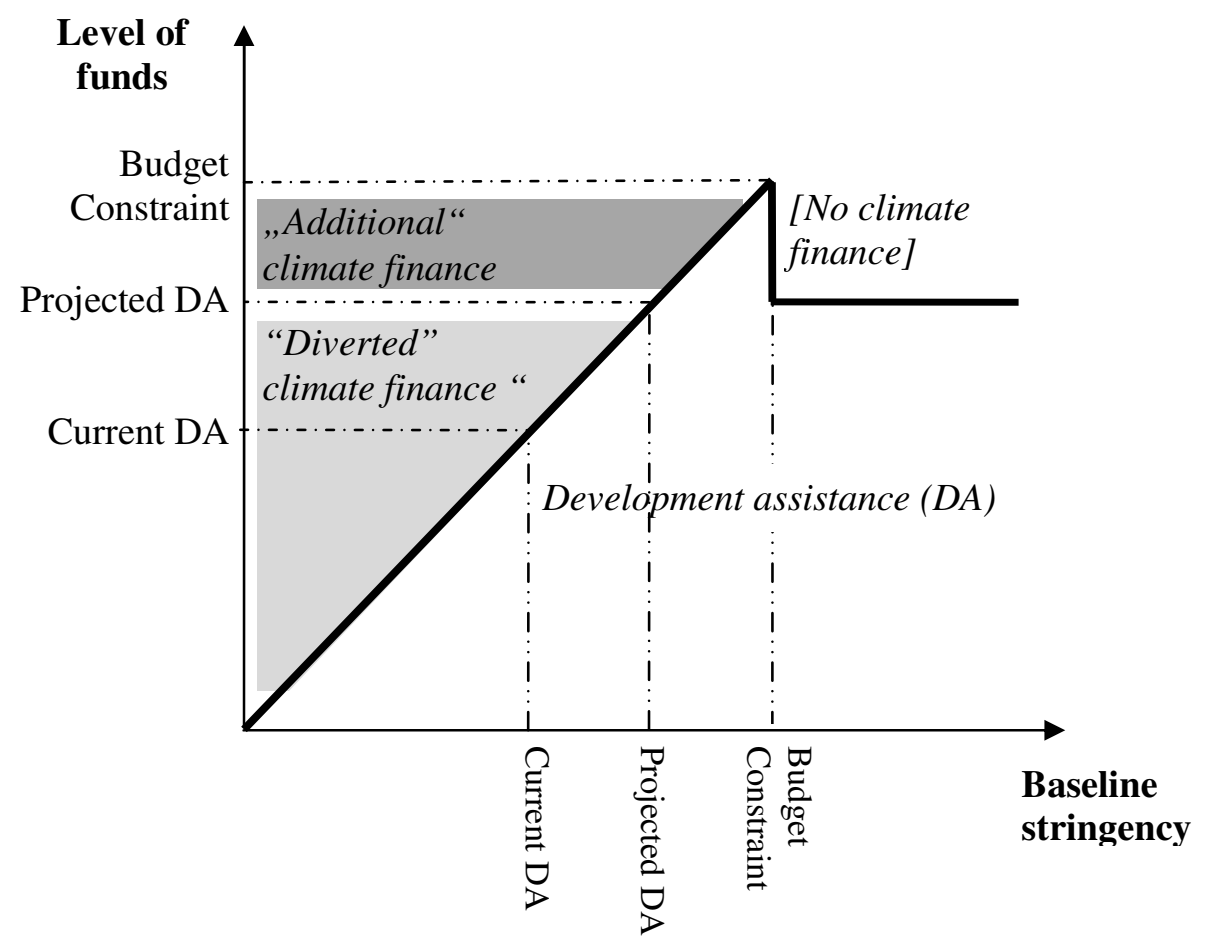

Figure 2: Historic ratio of ODA to GNI

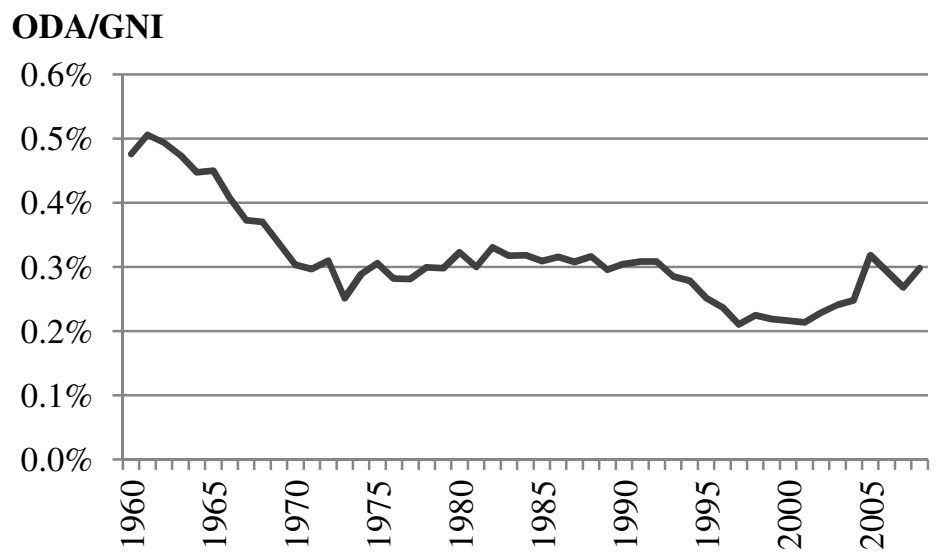

Sources: OECD (2010) for ODA and WB (2010) for GNI 
Figure 3: Possible projections of development assistance (straight line projections)

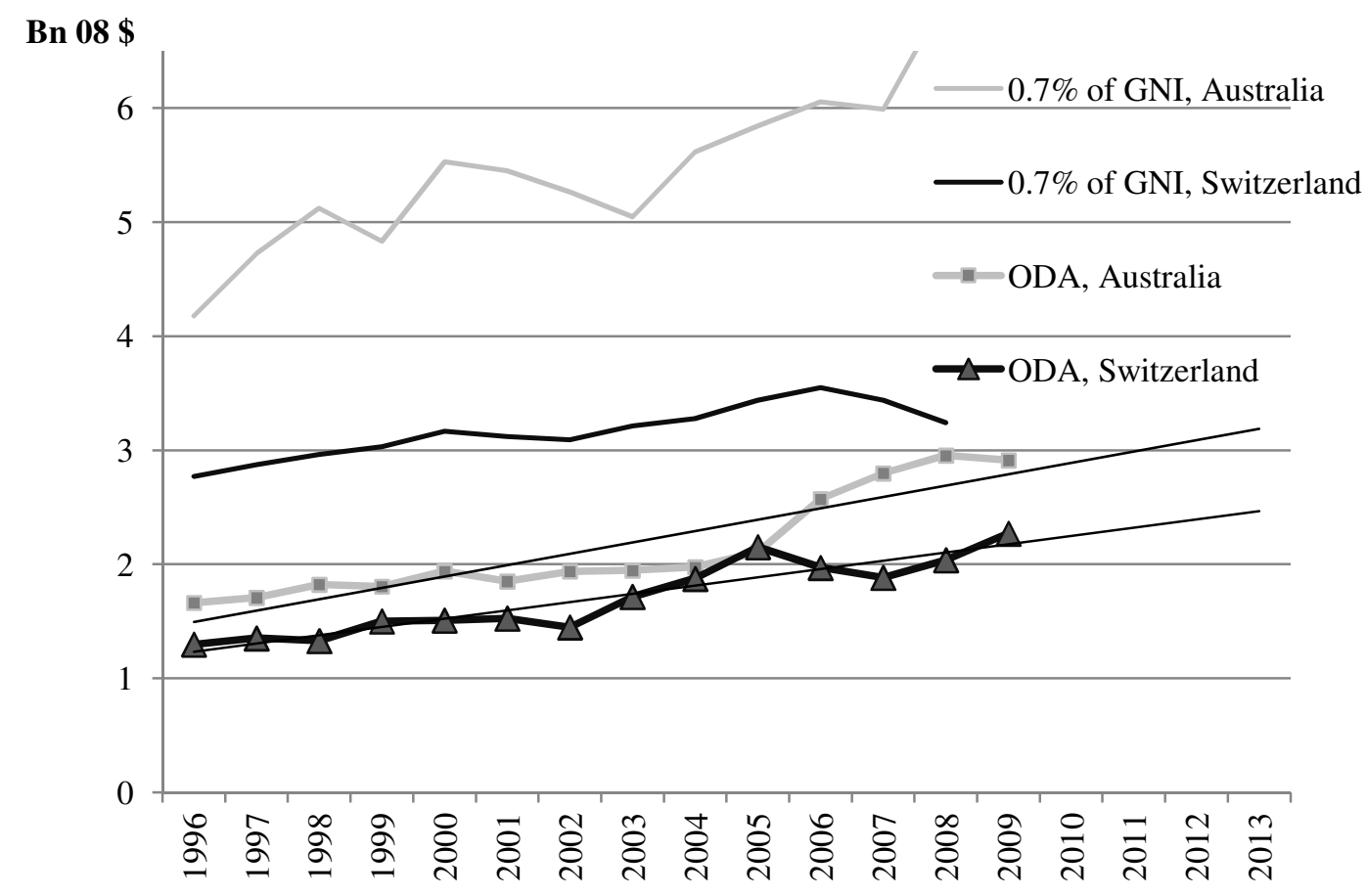

Source: Authors' analysis using data from OECD (2010) and WB (2010)

Figure 4: Projected development assistance, adjusted to GNI

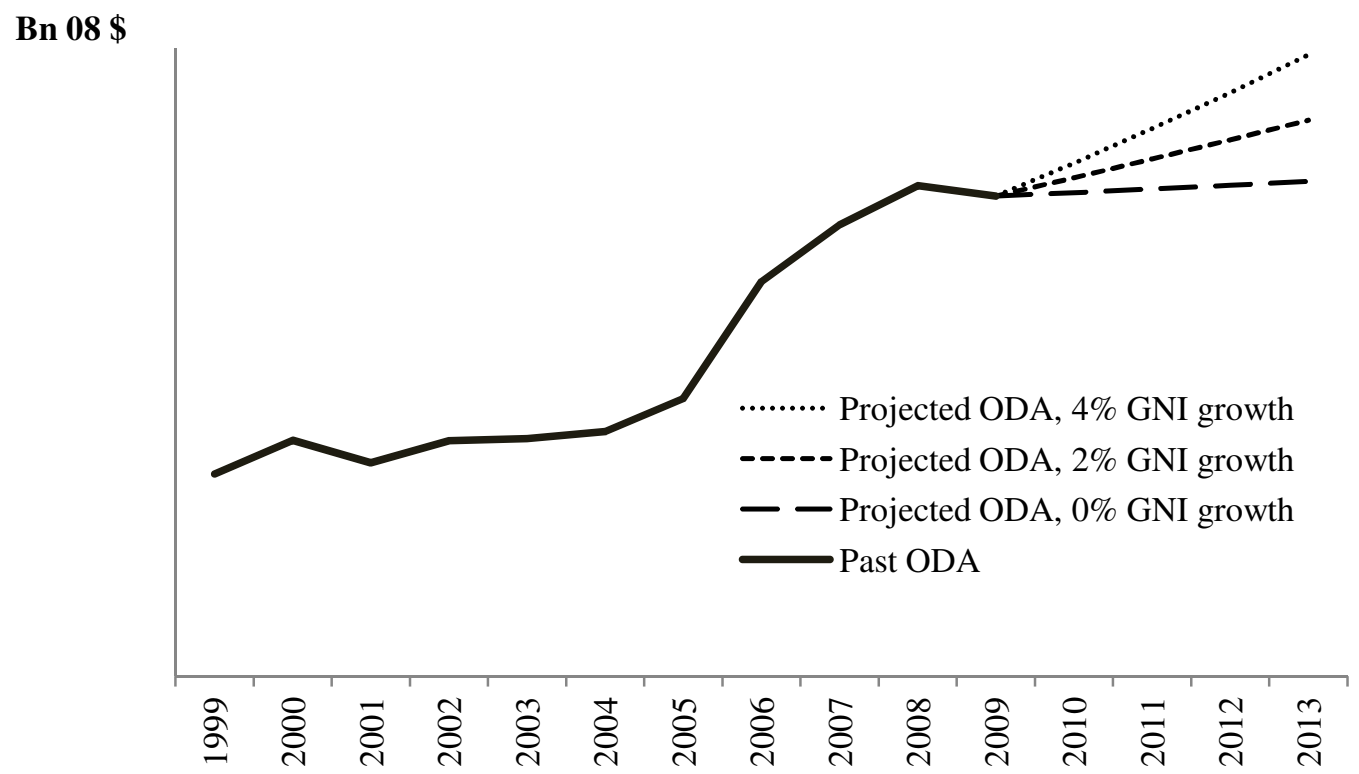

Source: Own graph, assuming ODA is projected to rise 
Table 1: Baselines for "new and additional" used by industrialized countries for fast-start funding

\begin{tabular}{|c|c|c|c|c|}
\hline \multirow[b]{2}{*}{ Country } & \multirow[t]{2}{*}{ Baseline definition $^{I}$} & \multirow[t]{2}{*}{$\begin{array}{l}\text { Baseline } \\
\text { stringency }^{2}\end{array}$} & \multirow{2}{*}{$\begin{array}{l}\text { Level of funds } \\
\text { allocated }^{3} \\
\% \text { of } 2009 \text { GNI }\end{array}$} & \multirow[t]{2}{*}{$\begin{array}{l}\text { Transparency } \\
\text { in reporting }\end{array}$} \\
\hline & & & & \\
\hline Australia & Existing aid budgets / no diversion & 2 & $0.039 \%$ & 1 \\
\hline Austria & Not specified & 0 & 0 & 0 \\
\hline Belgium & Current ODA, pre-COP15 commitm. & 2 & $0.015 \%$ & 0 \\
\hline Canada & pre COP15 commitments & 1 & 0 & 0 \\
\hline Denmark & above $0.7 \%$ ODA/GNI & 3 & $0.018 \%$ & 0 \\
\hline EU Commission & Above planned programmes & 2 & (not applicable) & 1 \\
\hline Finland & Above 2009 climate finance & 2 & $0.015 \%$ & 1 \\
\hline France & Not specified & 0 & $0.014 \%$ & 1 \\
\hline Germany & Not specified & 0 & $0.002 \%$ & 0 \\
\hline Hungary & Not specified & - & 0 & 0 \\
\hline Iceland & Not specified & 0 & 0 & 0 \\
\hline Ireland & Not specified & 0 & 0 & 0 \\
\hline Italy & Not specified & 0 & 0 & 0 \\
\hline Japan & Not specified & 0 & 0 & 0 \\
\hline Luxembourg & above $0.7 \%$ ODA/GNI & 3 & 0 & 0 \\
\hline Malta & Not specified & 0 & $0.002 \%$ & 0 \\
\hline Netherlands & above $0.7 \%$ ODA/GNI & 3 & $0.056 \%$ & 1 \\
\hline New Zealand & Not specified & 0 & 0 & 0 \\
\hline Norway & above $0.7 \%$ ODA/GNI & 3 & $0.060 \%$ & 1 \\
\hline Portugal & Not specified & 0 & $0.008 \%$ & 0 \\
\hline Slovenia & Not specified & 0 & 0 & 1 \\
\hline Spain & pre COP 15 commitments & 2 & $0.013 \%$ & 0 \\
\hline Sweden & above $0.7 \%$ ODA/GNI & 3 & $0.034 \%$ & 0 \\
\hline Switzerland & Existing ODA budgets & 2 & 0 & 0 \\
\hline United Kingdom & Past ODA, max. $10 \%$ of climate ODA & 1 & $0.018 \%$ & 1 \\
\hline United States & Not specified & 0 & $0.007 \%$ & 0 \\
\hline
\end{tabular}

${ }^{1}$ Source: WRI (2010); and Faststartfinance.org (2011) for: Australia, Canada, Finland, Iceland, Switzerland, United Kingdom. For Sweden and Norway, the " $0.7 \%$ ODA/GNI" baseline is not explicitly mentioned but is clear given current ODA contributions.

${ }^{2}$ No specification is scored as 0, lenient specification is scored as 1, stronger specification scored as 2; 0.7\% ODA/GNI scored as 3. Canada is only scored with 1 as baseline is below climate funds in past years. The UK rating is 1 since past pledges are included.

${ }^{3}$ Fast-start funds already allocated to projects or fund (Faststartfinance.org, 2011). Funds clearly not additional to existing ODA or commitments before Copenhagen were deducted.

${ }^{4}$ Rated 1 if both fast-start report and project or fund level details for 2010 finance available (Faststartfinance.org, 2011). 
Table 2: Assessment of baseline options

\begin{tabular}{|c|c|c|c|c|c|c|c|c|c|c|}
\hline Criterion & $\begin{array}{l}\text { 1) Additional } \\
\text { to develop't } \\
\text { assistance }\end{array}$ & $\begin{array}{l}\text { 2) New to exis- } \\
\text { ting flows and } \\
\text { pledges }\end{array}$ & $\begin{array}{l}\text { 3)Environ- } \\
\text { mental } \\
\text { Effectiveness }\end{array}$ & $\begin{array}{l}\text { 4) Distribu- } \\
\text { tional consid- } \\
\text { erations }\end{array}$ & $\begin{array}{l}\text { 5a) Political } \\
\text { acceptability } \\
\text { (North) }\end{array}$ & $\begin{array}{l}\text { 5a) Political } \\
\text { acceptability } \\
\text { (South) }\end{array}$ & $\begin{array}{c}5 b) \text { Feasibility } \\
\text { given budget } \\
\text { constraint }\end{array}$ & $\begin{array}{l}\text { 5c) Transpa- } \\
\text { rency: Clarity } \\
\text { of definition }\end{array}$ & $\begin{array}{l}\text { 5c) Transpar- } \\
\text { ency: Availa- } \\
\text { bility of data }\end{array}$ & $\begin{array}{l}\text { 5d) Consisten- } \\
\text { cy with other } \\
\text { regimes }\end{array}$ \\
\hline Means of assessment & $\begin{array}{c}\text { No DA } \\
\text { decrease }\end{array}$ & $\begin{array}{l}\text { No double } \\
\text { counting }\end{array}$ & $\begin{array}{l}\text { Funds for } \\
\text { mitigation \& } \\
\text { adaptation }\end{array}$ & $\begin{array}{l}\text { Shift of burden } \\
\text { away from } \\
\text { South }\end{array}$ & $\begin{array}{l}\text { Public } \\
\text { statements }\end{array}$ & $\begin{array}{c}\text { Public } \\
\text { statements }\end{array}$ & $\begin{array}{l}\text { Total of Devel- } \\
\text { opment \& } \\
\text { Climate Funds }\end{array}$ & Clarity & $\%$ available & $\begin{array}{l}\text { Consistency } \\
\text { with rules of } \\
\text { the DA regime }\end{array}$ \\
\hline \multicolumn{11}{|l|}{ Baseline Option } \\
\hline 1) $0.7 \% \mathrm{GNI}$ & + & + & - & + & - & + & - & + & + & - \\
\hline $\begin{array}{l}\text { 2) No agreed } \\
\text { baseline }\end{array}$ & - & $(-)$ & & $(-)$ & + & - & + & - & & + \\
\hline $\begin{array}{l}\text { 3) New UN } \\
\text { channels only }\end{array}$ & & & - & & - & & & + & + & + \\
\hline 4) No ODA counts & + & & $(-)$ & + & - & + & & + & + & - \\
\hline $\begin{array}{l}\text { 5) Current climate } \\
\text { finance }\end{array}$ & - & + & + & & & & & - & - & + \\
\hline $\begin{array}{l}\text { 6) Current develop- } \\
\text { ment assistance }\end{array}$ & - & & + & & + & - & + & & & \\
\hline $\begin{array}{l}\text { 7a) Updated projec- } \\
\text { tion of } D A\end{array}$ & + & & & + & & - & + & - & & $(-)$ \\
\hline $\begin{array}{l}\text { 7b) Pre-defined } \\
\text { projection of DA }\end{array}$ & + & & & + & & & + & + & & $(-)$ \\
\hline 8) New sources only & & + & $(-)$ & + & $(-)$ & $(-)$ & & + & + & + \\
\hline
\end{tabular}

+ criteria given, - clearly not given; blank cells means no clear or necessary impact of the baseline option on the criterion. (-) probably not given.

$D A=$ development assistance 
Annex: Regression of fast start climate funds (allocated amounts per GNI) on nations' baseline stringency, transparency, and level of current ODA

\begin{tabular}{lrl}
\hline & \multicolumn{2}{c}{ OLS } \\
Dependent variable & Coeff. & p-value \\
\hline ODA/GNI 2009 & 0.227 & $(0.02)$ \\
Transparency & 0.0002 & $(0.00)$ \\
Baseline_stringent & 0.0001 & $(0.15)$ \\
Constant & -0.0001 & $(0.08)$ \\
\hline N & 25 & \\
Adjusted $\mathrm{R}^{2}$ & 0.63 & \\
\hline
\end{tabular}

Allocated fast-start funds per GNI (non-additional funds deducted) as

dependent variable. Baseline_stringent $=1$ if Stringency level at least 2 (see

Table 1). All other independent variables (level of GNI, Climate Change

Performance Index) had clearly no significant influence on level of allocated

funds.

\section{Correlation matrixes}

\begin{tabular}{lllll}
\hline & $\begin{array}{l}\text { Fast-start } \\
\text { funds/GNI }\end{array}$ & ODA/GNI & Transparency & Baseline_stringent \\
\hline Fast-start funds/GNI & 1.0000 & & & \\
ODA/GNI & 0.6247 & 1.0000 & & \\
Transparency & 0.6167 & 0.1888 & 1.0000 & \\
Baseline_stringent & 0.5612 & 0.6115 & 0.2358 & 1.0000 \\
\hline obs=25) & & & &
\end{tabular}

(obs=25)

Faststartfinance.org, 2011. Fast Start Finance. Contributing countries.

$\langle$ http://www.faststartfinance.org/content/contributing-countries >, accessed 26th April 2011.

OECD, 2010. ODA by Donor. 〈http://stats.oecd.org/Index.aspx〉, accessed 31 st August 2010.

WB, 2010. World Bank Data. <http://data.worldbank.org/>, accessed 4th October 20102010. 